\title{
A Maintenance Time Measurement Methodology under the Combination of Ergonomics and Virtual Simulation
}

\author{
Zhou Xinxin, Zhou Dong, and Guo Ziyue
}

\begin{abstract}
The index of the maintenance time is very important in the maintenance design, a efficient maintenance time measurement methodology plays an important role in the early stage of the maintenance design, though there are many methods to measure the maintenance time ,they ignore the relationship between line production and the maintenance work. This paper proposes a corrective MOD method considering several man-machine factors, on the basis of the decomposition of maintenance task, the original MOD value of maintenance therbligs which described in virtual simulation environment can be got. With the influence factor of ergonomics and DELMIA analysis tools, the influence coefficients of several factors are discussed to correct MOD value. Finally, a case verifies the practicability and effectiveness of the method.
\end{abstract}

Index Terms-Maintainability, human factor, virtual reality, motion-time.

\section{INTRODUCTION}

Maintainability prediction is defined to estimate and calculate maintainability parameters of new products under a given working condition based on historical experience and the data of similar products. Maintenance time is a critical quantitative parameter in describing maintainability design. Long maintenance time will lead to huge loss, and influence the combat mission success rate and resource consumption, however the traditional way to measure maintenance time by the actual work has drawbacks 1). Measuring time by the actual maintenance work relies on physical prototype which is lagged, nevertheless Changing the design is very difficult and consumes lots of human and material resources also time. 2). The data used in the cumulative model is obtained by the statistical experiment of skilled worker. The development of the virtual reality provides an effective way to solve the problem. Virtual maintenance (VM)" is a computer and virtual reality-based application technology that simulates the maintenance process of the environment, and includes digital prototypes and virtual humans. Since the 1990s, many studies proposed a number of solutions using VR. Caudell and Mizell proved the effectiveness of using a VR system to provide instructions for wiring harness assembly [1]. Real-time immersive virtual environments (VEs), such as the CAVE have been used to assess the maintainability of virtual prototyp e[2]. Compared with the object-oriented prototype

Manuscript received June 8, 2016; revised October 12, 2016

Zhou Xinxin and Zhou Dong are with State Key Laboratory of Virtual Reality Technology and System Beijing, China (e-mail: 1470328933@qq.com).

Guo Ziyue is with Reliability and System Engineering College, China (e-mail: 490518193@qq.com). system called V-REALISM for maintenance training proposed by Li,J.R., et al. [3], a better solution has been presented by Abate, A.F., et al. [4], which combines VR techniques and haptic interaction to simulate process of product assembly maintenance in the aerospace industry. VM systems have been applied in maintenance process simulation [5], maintenance planning [6], and maintenance training Amos, H.C.N. et al. [7] have established a machine service support system that demonstrates advanced use of 3D graphical simulation tools in the resource domain, and expends the use of simulation modules from the system design and development phase into operation phase. Bourdot, P. et al. [8] presented an approach for integrating VR and computer-aided design (CAD), allowing intuitive and direct 3D edition on CAD objects within VEs. For the second, the difference between maintenance process and line production should be considered. The maintenance time is greatly influenced by the maintainability of the product. The method used in the line production is MTM (Method time Measurement) [9], which should be corrected in the maintenance time measurement. MTM is put forward by B.S.Q. Elzendoorn and Delphine Keller. A lot of literatures discussed MTM. In 1928, A. B. Segur raised the Motion-Time Mechanism in his Ph.D. thesis [10]. The line production is relatively easy and not influenced by many factors, however the maintenance work is very complex and the maintenance worker need high skills to complete it ,The MOD divides the motion more accurately, which is more suitable to the maintenance work. Given the observation above, this paper proposes a new way to measure maintenance time in the virtual environment.

\section{Framework of the Proposed Methodolog}

The Fig. 1 show the framework of this paper, which consist of four parts: support method, support data, maintenance measurement time and output. Support data provide the data for the research, which are maintenance procedure, human model and ergonomics data; Support method is the MOD method, provides the key way to measure each maintenance virtual simulation therbligs; The section of the method is how to calculate the maintenance time of each therbligs and determine the correction factor of the maintenance time. This will be discussed in detail; Output introduces the possible output of the proposed method.

\section{Time Measurement of Maintenance TASK}

Using the MOD to measure the maintenance time regards human action as the core, so the decomposition of the maintenance task is the first step[11],then we can determine the value of the MOD for each therbligs, and the 
maintenance time need to be corrected considering the influence time of visibility, workspace and human posture.

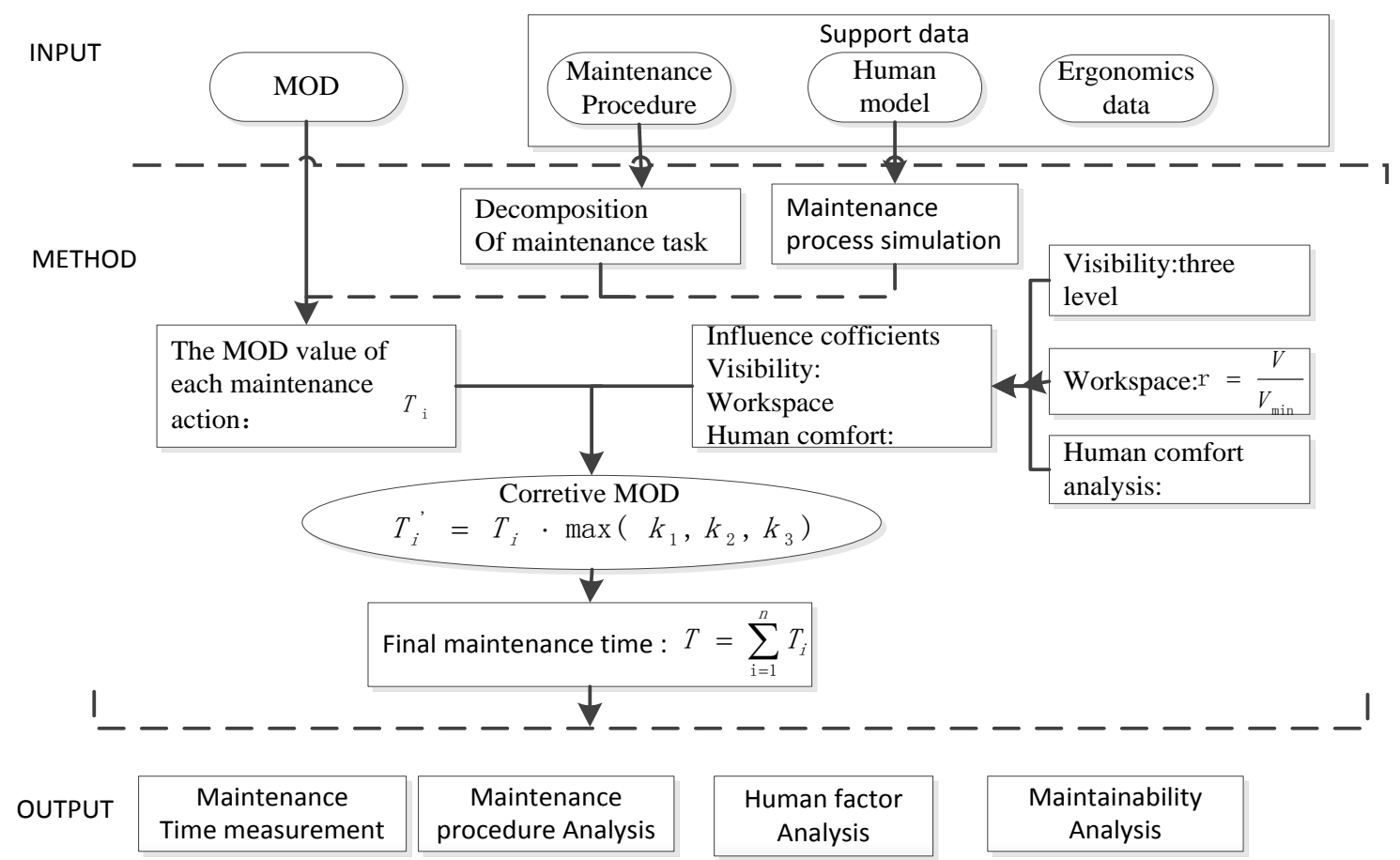

Fig. 1. Frame work of the proposed methodology.

\section{A. Decomposition of the Maintenance Task}

Maintenance process should be decomposed before measuring maintenance time According to the traditional maintenance process decomposition, a maintenance process in general can be broken down into three levels: maintenance event, maintenance work and basic maintenance operation. In the process of the decomposition, the basic maintenance operation is the lowest level, the accuracy of the basic maintenance time results directly influence the final prediction result. However the prediction of the basic maintenance operation is mainly predicted according to the engineering experience and lack a Scientific and effective measurement method. Basic maintenance operation is directly related to the product meanwhile. For example, turning the screw, the complete process is different when operate different product. This makes maintenance time of the same basic maintenance operation different, So we need to study the basic maintenance measurement method. According to the hierarchical thinking, bottom-up building maintenance process simulation model, we determine the classification and time of maintenance therbligs, which has no relation to specific object. We finally decompose maintenance process into four layers: maintenance event layer, maintenance work layer, basic maintenance operation layer and maintenance therbligs layer.

For example, in the level of maintenance event ,replacing an unserviceable component can be divided into Fault location, Fault isolation, Remove component timing, inspection, this is Maintenance work layer. Further removing the component can be divided into open the pressure machine covers, free the fixed bolted failure parts ,remove clamp failure, separate

Failure parts.. this is the basic maintenance operation layer, Further opening the pressure cover can also be divided into move(walk to operation location ),grasp(Stretch hand to grasp the target ),Disassembling operation(open action), let go (release object and return to normal position), this is the level of maintenance therbligs layer.

According to maintenance work, this paper divides maintenance work into four parts considering characteristics of MOD method: mobile therbligs, posture-adjustive therbligs and operational therbligs. The detail description is shown Fig. 2.

\section{B. Corrective MOD}

The basic principle of the MOD is:

1) All operation actions of all people, contains basic movements can be divided into 21 basic action through lots of experiments.

2) Under the same condition, different people doing the same movement nearly take the same time.

3) The time of different movement is proportional to each other.

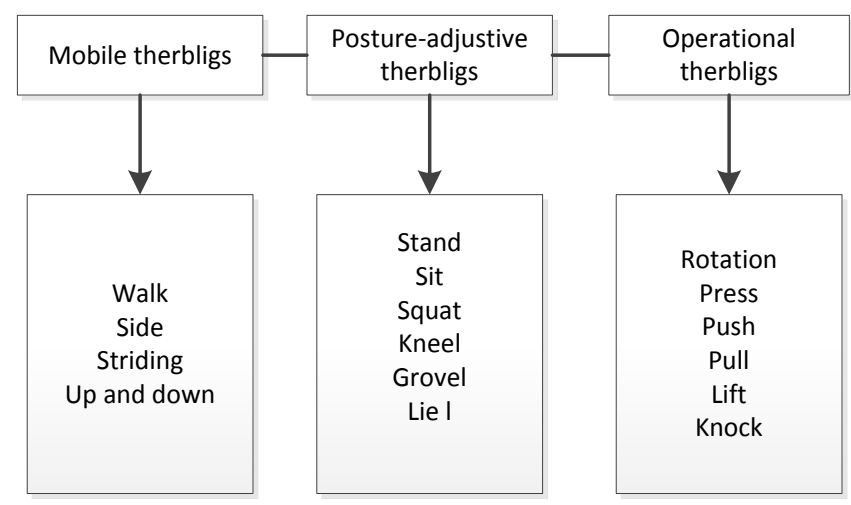

Fig. 2. Human action therbligs.

TABLE I: THE MOD METHOD CLASSIFICATION OF BASIC THERBLIGS

\begin{tabular}{cccc}
\hline \hline \multicolumn{2}{c|}{ Classification } & Details & Sign \\
\hline Move & Move & Finger movement & M1
\end{tabular}




\begin{tabular}{|c|c|c|c|}
\hline \multirow[t]{5}{*}{ action } & & Wrist movement & M2 \\
\hline & & Forearm movement & M3 \\
\hline & & Upper arm movement & M4 \\
\hline & & $\begin{array}{c}\text { Straighten the arm } \\
\text { movement }\end{array}$ & M5 \\
\hline & Reflex motion & $\begin{array}{c}\text { Continuous repeatedly } \\
\text { reflex action }\end{array}$ & $\begin{array}{l}\text { M1/2、 } \\
\text { M1、M2 }\end{array}$ \\
\hline \multirow{6}{*}{$\begin{array}{l}\text { End up } \\
\text { action }\end{array}$} & \multirow{3}{*}{$\begin{array}{l}\text { Grasping } \\
\text { motion }\end{array}$} & Touch or contact & G0 \\
\hline & & Grab without attention & G1 \\
\hline & & Complicated capture & G3 \\
\hline & \multirow{3}{*}{$\begin{array}{l}\text { Putting } \\
\text { motion }\end{array}$} & Simple placement & $\mathrm{P} 0$ \\
\hline & & $\begin{array}{c}\text { Complex placement, as } \\
\text { alignment } \\
\end{array}$ & $\mathrm{P} 2$ \\
\hline & & $\begin{array}{c}\text { Placement aimed at } \\
\text { assemble }\end{array}$ & P5 \\
\hline \multirow{10}{*}{$\begin{array}{l}\text { Other } \\
\text { action }\end{array}$} & Feet motion & Cadence motion & F3 \\
\hline & Thigh motion & Walk action & W5 \\
\hline & & Visual inspection & E2 \\
\hline & $\begin{array}{l}\text { Independent } \\
\text { motion (other }\end{array}$ & correction & $\mathrm{R} 2$ \\
\hline & $\begin{array}{l}\text { actions have } \\
\text { to stop ) }\end{array}$ & Judgment and reaction & D3 \\
\hline & & Press down & A4 \\
\hline & \multirow{3}{*}{$\begin{array}{l}\text { Body } \\
\text { movements at } \\
\text { the same time }\end{array}$} & Spins & $\mathrm{C} 4$ \\
\hline & & $\begin{array}{c}\text { Stoop /curve body } \rightarrow \\
\text { Stand up }\end{array}$ & B17 \\
\hline & & Sit down $\rightarrow$ Get up & $\mathrm{S} 30$ \\
\hline & $\begin{array}{l}\text { Additive } \\
\text { factor }\end{array}$ & gravimetric factor (Load) & L1 \\
\hline
\end{tabular}

The MOD choose the time of lifting a finger as the basic units, the time is $0.129 \mathrm{~s}$ and is regard as a MOD[12]..However the time is not absolutely, and can be modified according to the practical situation. The MOD method divides human action into 21 categories including 11 basic therbilgs and 10 other auxiliary therbligs. 11 basic therbligs contains 5 mobile therbligs and 6 end therbligs. Specific definitions and symbols of each therbligs are shown in table 1.It is convenient to use MOD method to analyze actions. We can determine the the MOD value as long as we know which type of the action is. The MOD method will also encounter the consumption time which is not caused by movements but necessary, which is defined in the below Table II.

\section{Workspace Factor Analysis \\ 1) Visibility factor analysis}

Visibility is one of the most important influence factors in maintenance work. In the maintenance work, lots of operation areas have poor visibility, which make the maintenance work difficult and influence the time greatly. Ergonomics show the degree of visibility can be divided into three levels

TABLE II: ADD SYMBOLS AND DEFINITIONS

\begin{tabular}{|c|c|c|c|}
\hline Definition & Sign & Details & Samples \\
\hline Delayed & $\mathrm{BD}$ & movements, & Right hand \\
\hline
\end{tabular}

\begin{tabular}{|c|c|c|c|}
\hline & & $\begin{array}{l}\text { another hand in the } \\
\text { stopped state, don't give } \\
\text { time }\end{array}$ & Left hand BD \\
\hline Maintain & $\mathrm{H}$ & $\begin{array}{l}\text { Fixed state with hand } \\
\text { holding or grasping } \\
\text { objects, mainly refers to } \\
\text { the action of support and } \\
\text { fixed, don't give time }\end{array}$ & $\begin{array}{l}\text { Left hand } \mathrm{H} \\
\text { Right hand } \mathrm{P} 2\end{array}$ \\
\hline $\begin{array}{c}\text { Effective } \\
\text { time }\end{array}$ & UT & $\begin{array}{l}\text { Except movement of } \\
\text { serviceman, inherent } \\
\text { additional time caused by } \\
\text { machines or other } \\
\text { technical requirements } \\
\text { instead of action } \\
\text { produced, need to } \\
\text { measure time accurately. } \\
\text { Such as mechanical } \\
\text { working time, soldering, } \\
\text { riveting, testing, coating, } \\
\text { etc. }\end{array}$ & $\begin{array}{l}\text { tin soldering } \\
\text { time UT or } \\
\text { Instrument } \\
\text { testing time }\end{array}$ \\
\hline
\end{tabular}

1 within the $15^{\circ}$ scope cone, is the best vision field; 2 within the $30^{\circ}$ scope cone, is the largest vision field;

3 outside the $30^{\circ}$ scope cone, is the invisible field.

The virtual simulation software DELMIA support the visibility analysis tools, which can show us the detail information of scope cone, as shown in Fig. 3.

Assuming the distance between maintenance personnel's eyes and maintenance operation object is $h$, the area of the best vision field, the largest vision field and the invisible field is $\mathrm{S} 1, \mathrm{~S} 2$ and $\mathrm{S} 3$, then:

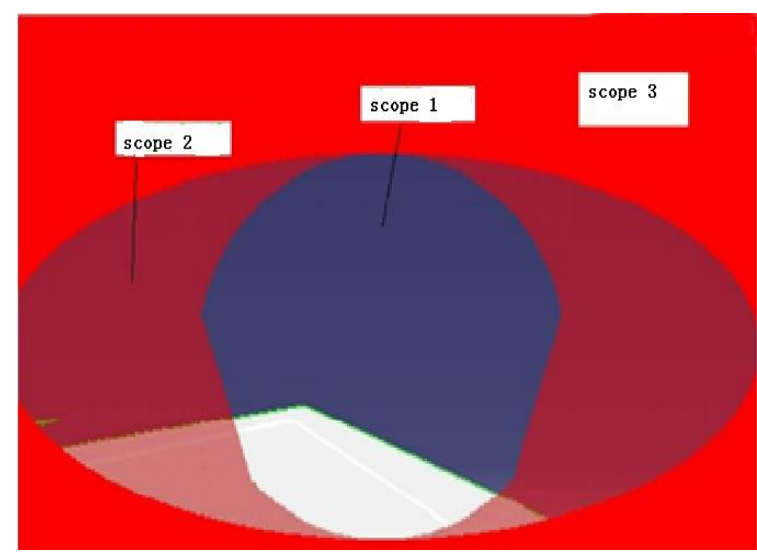

Fig. 3. Vision scope

TABLE III: VISIBILITY INFLUENCE COEFFICIENT

\begin{tabular}{cll}
\hline \hline Scope analysis area & Visibility level & Influence coefficient \\
\hline $15^{\circ}$ scope cone & Good & 1 \\
\hline Other scope cone & Normal & 1.4679 \\
\hline \hline$S_{1}=\pi \cdot\left(h \cdot \tan 15^{\circ}\right)^{2}$ & 2.4313 \\
$S_{2}=\pi \cdot\left(h \cdot \tan 15^{\circ}\right) \cdot\left(h \cdot \tan 30^{\circ}\right)$ \\
$S_{3}=4\left(h \cdot \tan 30^{\circ}\right)^{2}$
\end{tabular}


When the maintenance worker is in the best vision field, the visibility won't influence coefficient. WhileS2/S1 $=\tan 30 / \tan 1$

$\mathrm{k}_{12}=\sqrt{2.1547}=1.4679 k_{13}=\sqrt{5.9113}=2.4313$

When separately considering the impact of visibility, the value of MOD need to be modified to get actual time. So we can define $15^{\circ}$ scope as the good level, $30^{\circ}$ scope as the normal level, other scope as the bad level. And the coefficient is shown in the above Table III.

\section{2) Workspace}

Work space is defined the actual space for maintenance personnel, which is an important influence factor for maintenance. Operation of the maintenance worker in an environment where interference between human and machine parts is a major concern, sufficient operating room has to be reserved to avoid collisions during maintenance process [13]. What's more, the space reserved for the maintenance motions may cause effect on operator's comfort feelings and performance. Enough maintenance space for maintainers has to be reserved for the maintainers to ensure easy of operation, safety, comfort, and performance and so on. If the operator operate in the bad work space, he have to adjust his gesture to complete the work, which lead to maintenance time extending .certainly.

In ergonomics, scholars generally judge the degree of workspace by collision and interference [14]. And quantitative evaluation can be assessed by workspace ratio [15].

$$
r=\frac{V}{V_{\text {min }}}
$$

Maintenance operation is mainly divided into two kinds: bare-hand operation and with tool operation. Different kind has different way to calculate. The sizes of the maintainer's hand are obtained through statistic data or related standards. Fig. 4 shows the schematic diagram of the sizes.

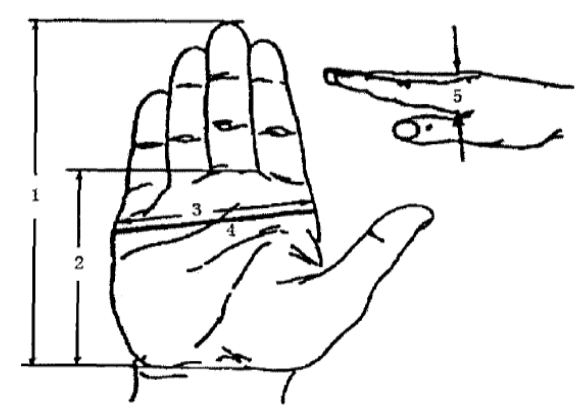

Fig. 4. The schematic diagram of hand sizes.

Bare-hand minimum workspace can be set as a cube model. Length (defined as 1 ) is the sum of hand length (named as $l_{h}$ ) and palm length (named as ${ }_{p}$ ); width (defined as w) is equal to the hand width (named as ${ }^{W_{h}}$ ); height (defined as $\mathrm{h}$ ) is three times as hand thickness (named as $h_{t}$ ). So the bare-hand operation minimum workspace calculation expression is:

$$
V_{\min }=1 \cdot w \cdot h=3\left(l_{h}+l_{p}\right) \cdot w_{h} \cdot h_{t}
$$

Assuming maintenance personnel use standard tools to operate the failed units. The size data of the standard tools can be got through relative industry standard. The with tool operation minimum workspace expression is:

$$
V_{\text {min }}=I_{t} \cdot \max \left(w_{t}, w_{h}\right) \cdot \max \left(h_{t}^{t}, 3 h_{t}\right)
$$

where $l_{t}$ is the tool's length; $w_{t}$ is the tool's width; $h_{t}^{t}$ is the thickness of the tool.

By studying the ergonomics data, the influence of workspace to the maintenance time can be divided into three levels., good, normal ,bad. And the description are:

Good: rm and tools of the maintenance personnel have enough operation in the natural condition, is convenient to complete maintenance operations; Normal: Maintenance personnel can make arm and tool seldom collide the surrounding equipment adjusting within a certain permitted scope, is convenient to complete maintenance operations Bad: Arm and tool still cannot avoid colliding the surrounding equipment within a certain permitted scope, is difficult to finish the maintenance operation.

And the detail of the influence coefficient is: shown in the

\begin{tabular}{|c|c|c|}
\hline Workspace level & $\mathrm{r}$ & influence coefficient \\
\hline Good & $>1.8$ & 1 \\
\hline Normal & $1.5<\mathrm{r}<1.8$ & 1.1 \\
\hline bad & $<1.5$ & 1.3 \\
\hline
\end{tabular}
Table IV.

TABLE VI: VISIBILITY INFLUENCE COEFFICIENT

As a result, the workspace factor's influence coefficient is: $\mathrm{k} 21=1, \mathrm{k} 22=2.4539, \mathrm{k} 23=6.2231$. And the specific data can be gained by virtual simulation software DELMIA. Through simulating therbligs which decomposed from maintenance task, maintenance personnel can receive detail human data and workspace data, as shown in Fig. 5.

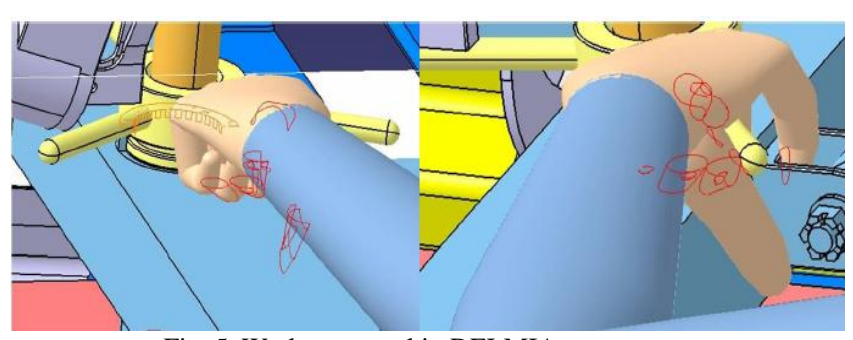

Fig. 5. Workspace tool in DELMIA.

\section{3) Human posture factor analysis}

Human posture comfort analysis plays an important role in maintenance operation evaluation. Human posture analysis considers the comfort level and fatigue level of maintenance personnel during maintenance process. Bad working posture will not only cause injury to muscles and skeletons but also lead to psychological and physiological fatigue which makes maintenance therbligs twist and working efficiency decrease. Thus, the comfort level of human working posture makes a big influence on maintenance time measurement. In the table 5 green indicates that human posture is comfortable, and this posture can be received; yellow means that human posture is a little uncomfortable in a certain, but this posture 
is in the received scope; brown state that the comfort level of this posture is poor, needs improve quickly; red explains maintenance personnel keeps a very bad working posture, posture needs to change right now in order to ensure maintenance safety.

TABLE V: DETAIL INFORMATION OF RULA

\begin{tabular}{c|c|c|c|c|c|c|c}
\hline \hline \multirow{2}{*}{ limb } & \multirow{2}{*}{$\begin{array}{c}\text { Result } \\
\text { range }\end{array}$} & \multicolumn{6}{|c}{ Color relative to result } \\
\cline { 3 - 8 } & 1 & 2 & 3 & 4 & 5 & 6 \\
\hline $\begin{array}{c}\text { Upper } \\
\text { arm }\end{array}$ & $1-6$ & green & green & yellow & yellow & red & red \\
\hline Forearm & $1-3$ & green & yellow & red & & & \\
\hline Wrist & $1-4$ & green & yellow & brown & red & & \\
\hline Wrist & $1-2$ & green & red & & & & \\
twist & & & & & & & \\
\hline Neck & $1-6$ & green & green & yellow yellow & red & red \\
\hline body & $1-6$ & green & green & yellow yellow & red & red \\
\hline \hline
\end{tabular}

Then, RULA method divides these limb results into two groups, and analysis these result integrated and comprehensively, which is shown in the below figure 6.And The total score of the waist neck and upper arm is shown in the Table VI.

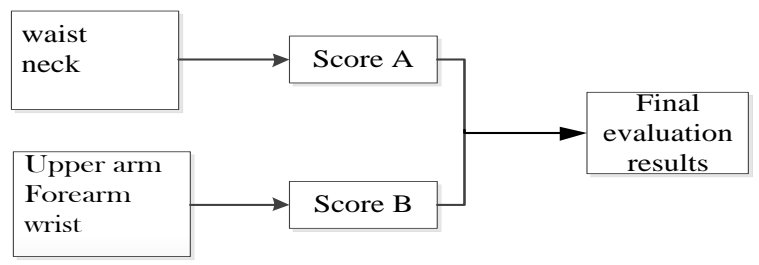

Fig. 6. RULA evaluation process.

\begin{tabular}{c|c|c|c|c|c|c|c}
\multicolumn{7}{c}{ TABLE VI: FINAL RESULT } \\
\hline \hline \multirow{2}{*}{ limb } & \multirow{2}{*}{$\begin{array}{c}\text { Result } \\
\text { range }\end{array}$} & \multicolumn{5}{c}{ Color relative to result } \\
\cline { 3 - 8 } & 1 & 2 & 3 & 4 & 5 & 6 \\
\hline $\begin{array}{c}\text { Upper } \\
\text { arm }\end{array}$ & $1-6$ & green & green & yellow & yellow & red & red \\
\hline Forearm & $1-3$ & green & yellow & red & & \\
\hline Wrist & $1-4$ & green & yellow & brown & red & \\
\hline Wrist & $1-2$ & green & red & & & \\
twist & $1-6$ & green & green & yellow & yellow & red & red \\
\hline Neck & $1-6$ & green & green & yellow & yellow & red & red \\
\hline body & $1-6$ &
\end{tabular}

Lynn McAtamney and Dr. E Nigel Corlett (the authors of RULA) finally divided the comfort quantitative result into five parts and gave some suggestion. According to the ergonomics data and the influence to maintenance time, table 7 presents the influence coefficient of human posture factors which influence the maintenance time.

\section{Determine MOD Value}

As visibility, workspace and human posture don't have directly interactive relationship when these three factors influencing on maintenance time measurement, this paper assumes that visibility, workspace and human posture are three mutual independent factors in maintenance time measuring. Therefore, the MOD value can be calculated as following:

1) When finishing decomposing maintenance task into therbligs, maintenance personnel can simulate these therbligs in DELMIA;

2) For the ith maintenance therbligs, look up table 3 , table 4 and table 10, finding out the influence coefficients of visibility, workspace and human posture through ergonomics tools in DELMIA;

3) According to the basic therbligs, look up Table I, determine the basic MOD value, then converse it into consuming time, defined as $T_{\mathrm{i}}$.

4) Visibility, workspace and human posture these three factors often occurred interactively. Bad visibility usually causes workspace and human posture problems while bad workspace situation may lead to uncomfortable human posture. Considering influence factors integrative, the final maintenance time measurement result can be corrected by the maximum coefficient.

5) Weighting basic time of the ith maintenance therbligs with three influence coefficients comprehensively, gain the correct $i$ th consuming time, defined as $T_{\mathrm{i}}^{\prime}=T_{i} \cdot \max \left(k_{1}, k_{2}, k_{3}\right)$.

6) Add all maintenance time of each therbligs, the final maintenance time can be calculated as $T=\sum_{i=1}^{n} T_{i}$

\section{CASE Study}

The APU motor starter of an air bus is installed at the Empennage of the plane. It is fixed by 8 hexagon bolt on the bracket. The weight of APU is about $20 \mathrm{~kg}$. Maintenance personnel has already contract virtual simulation maintenance environment in DELMIA.

\section{A. Decomposition of the Maintenance Process}

According to the related chapters content about APU motor starter in the maintenance manual of this air bus, its maintenance process can be decomposed as Fig. 7

\section{B. Establishment of the Simulation Model}

Single maintenance personnel can finish disassembling the APU motor starter with only hexagon wrench. According to the human data in GB-10000-1988, we build a Chinese maintenance personnel model in DELMIA.

Then we set up Human Task which is corresponded to the basic maintenance work and establish the maintenance therbligs, finally establish the simulation model of the whole maintenance process. As is shown in the below Fig. 8.

\section{Maintenance Therbligs Time Measurement}

In DELMIA, a maintenance therbligs is named as "MoveToPosture" (MTP). We can analyze itbasic MOD value and fill the basic MOD value in the third blank space in the property dialogue box. 
TABLE VII: HUMAN POSTURE FACTOR LEVEL AND INFLUENCE COEFFICIENT

\begin{tabular}{ccccc}
\hline \hline Activity result & Final result & Risk level & suggestion & Influence coefficient \\
0 & 1 & No risk & No need to improve & 1 \\
1 & $2 \sim 3$ & low & Maybe need to improve & 1.1 \\
2 & $4 \sim 6$ & middle & Need to improve & 1.2 \\
3 & $7 \sim 9$ & high & Need to improve quickly & 1.3 \\
4 & $10 \sim 11$ & Polar high & Need to improve right now & 1.4 \\
\hline \hline
\end{tabular}

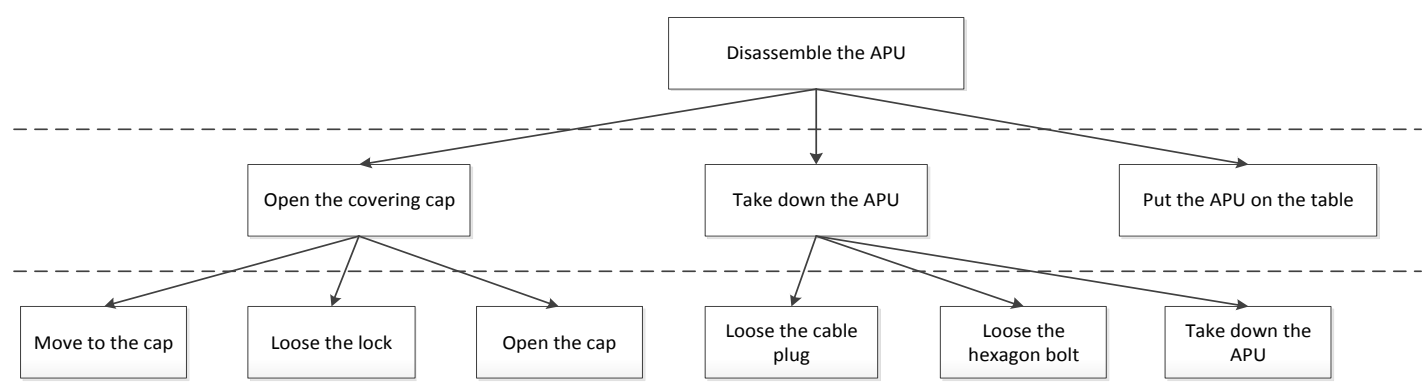

Fig. 7. Decomposition figure of the maintenance process.

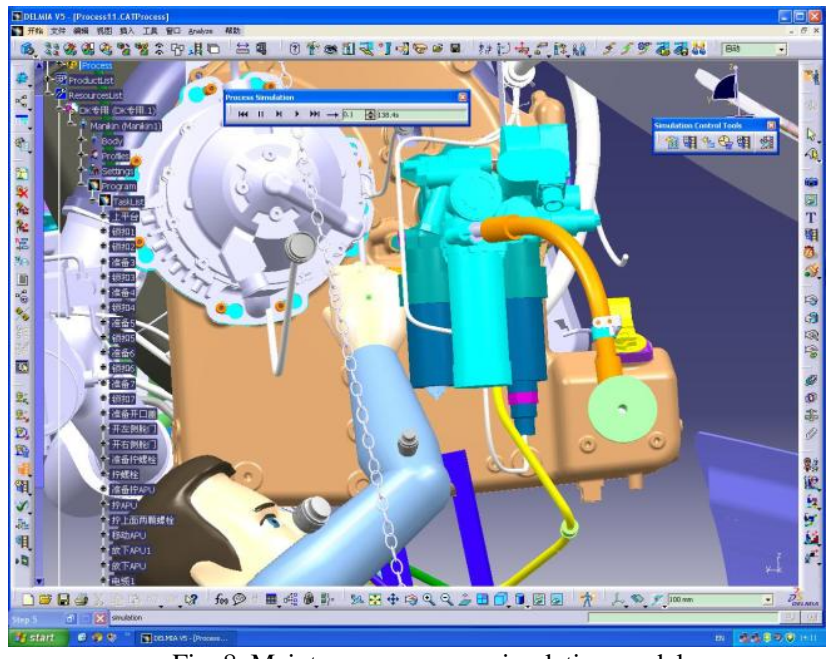

Fig. 8. Maintenance process simulation model.

Based on this method, the basic MOD value of each MTP can be filled in the property dialogue box. Then, we choose one human task under ProcessList in P.P.R environment.

After we get the basic MOD value, the next step is correcting MOD value by influence coefficients of visibility, workspace and human posture. Taking a screw MTP as an example, the maintenance therbligs is in the Fig. 8.

In the figure 8 , maintenance tool is ratchet wrench, its length is $200 \mathrm{~mm}$, width is $30 \mathrm{~mm}$ and thickness is $15 \mathrm{~mm}$. According to the content in "workspace factor analysis", the minimum workspace is:

$$
V_{\text {min }}=200 \times 83 \times 3 \times 28=1.3944 \times 10^{6}\left(\mathrm{~mm}^{3}\right)
$$

And the workspace is:

$$
V=\left(260 \times 260 \times 300-\pi 120^{2} * 300\right) / 4=1.6771 \times 10^{6}\left(\mathrm{~mm}^{3}\right)
$$

So the workspace ratio is:

$$
r=\frac{V}{V_{\min }}=\frac{1.6771}{1.3944}=1.203<1.5
$$

And the workspace influence coefficient is $\mathrm{k}_{2}=1.3$. Open the tool eye vision

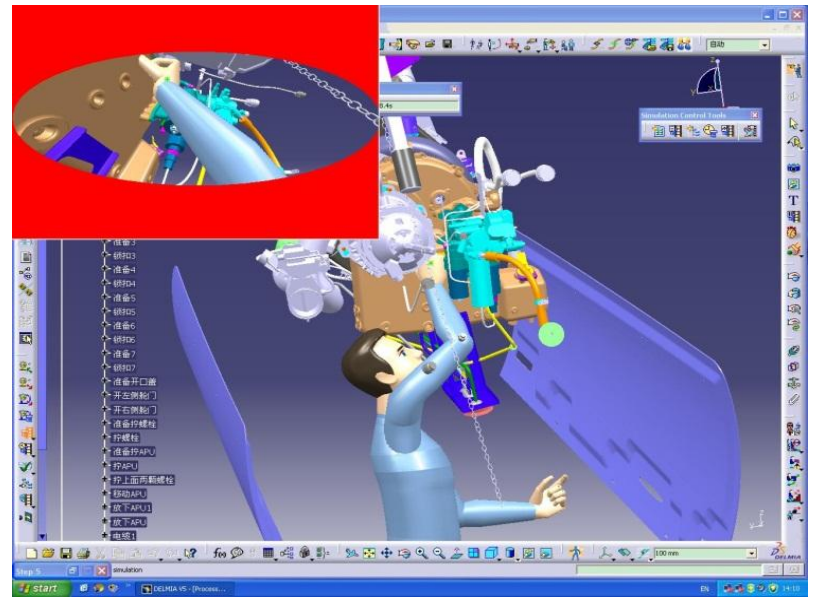

Fig. 9. Visibility condition.

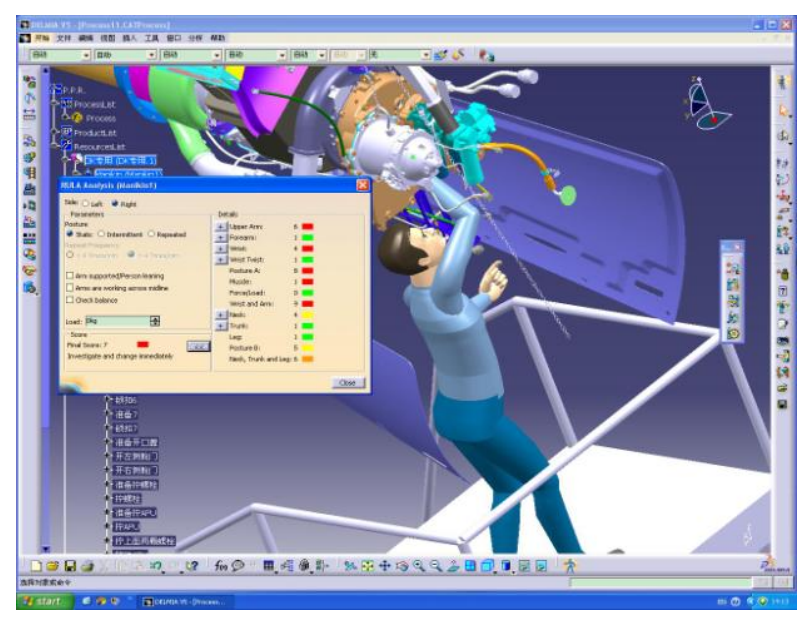

Fig. 10. RULA analysis result.

According to the Fig. 9, we can find the scope is bad, so we can get the visibility $\mathrm{k}_{1}=2.4313$ according to table 3 . And we open the human ergonomics tool and choose the RULA analysis tool; the result can be seen in Fig. 10.

We open the human ergonomics tool and choose the RULA analysis tool, Look up to the contents in chapter "human posture analysis", the final RULA quantitative result is 8 , and 12 the human posture influence coefficient is $k_{3}=1.3$. 
As the basic MOD value of this maintenance therbligs is belongs to $\mathrm{M} 2$, so the basic MOD consumption time is 2 MOD. The corrective MOD value is: $T_{\mathrm{i}}^{\prime}=T_{i} \cdot \max \left(k_{1}, k_{2}, k_{3}\right)=2 \times 2.4313=4.8626 \mathrm{MOD}$ Then we can measure all maintenance therbligs MOD value in the same way.. We use Delmia, we can get the basic maintenance work measurement time and corrective time is presented in table 8.we can see that maintenance time measured directly by MOD method is 202.659 s; while the maintenance time measured by corrected MOD method is $289.734 \mathrm{~s}$, which is closer to the actual maintenance time 296.266s than the previous one.

TABLE VIII: Basic Maintenance Time MEASUREMENT Results

\begin{tabular}{|c|c|c|c|c|}
\hline $\begin{array}{c}\text { Basic } \\
\text { maintenance } \\
\text { work }\end{array}$ & $\begin{array}{l}\text { Basic } \\
\text { MOD } \\
\text { value }\end{array}$ & $\begin{array}{c}\text { Basic } \\
\text { consumption } \\
\text { time/s }\end{array}$ & $\begin{array}{l}\text { Corrective } \\
\text { consumption } \\
\text { time/s }\end{array}$ & $\begin{array}{c}\text { Actual } \\
\text { consumption } \\
\text { time/s }\end{array}$ \\
\hline $\begin{array}{l}\text { Going up the } \\
\text { operation } \\
\text { platform }\end{array}$ & 595 & 76.755 & 82.431 & 84.773 \\
\hline $\begin{array}{c}\text { Opening } \\
\text { seven cap } \\
\text { locks } \\
\end{array}$ & 235 & 30.315 & 36.378 & 37.612 \\
\hline $\begin{array}{l}\text { Opening the } \\
\text { left side } \\
\text { cabin door }\end{array}$ & 55 & 7.095 & 10.062 & 11.300 \\
\hline $\begin{array}{l}\text { Opening the } \\
\text { right side } \\
\text { cabin door }\end{array}$ & 55 & 7.095 & 10.062 & 11.300 \\
\hline $\begin{array}{c}\text { screwing } 8 \\
\text { hexagon } \\
\text { bolts }\end{array}$ & 415 & 53.535 & 107.973 & 105.587 \\
\hline $\begin{array}{c}\text { screwing } \\
\text { APU }\end{array}$ & 18 & 2.322 & 3.225 & 3.750 \\
\hline $\begin{array}{c}\text { moving } \\
\text { cables }\end{array}$ & 49 & 6.321 & 9.546 & 10.465 \\
\hline $\begin{array}{l}\text { putting APU } \\
\text { to the } \\
\text { operation } \\
\text { platform } \\
\end{array}$ & 149 & 19.221 & 30.057 & 31.479 \\
\hline & 1571 & 202.659 & 289.734 & 296.266 \\
\hline
\end{tabular}

\section{CONClusion AND Future WORK}

This paper proposed a methodology for measuring the maintenance time in virtual simulation environment. A maintenance action decomposition of maintenance tasks and corrective MOD with factors that influence the maintenance time are discussed. Finally a case study verifies the effectiveness of the proposed methodology.

Several areas need to be studied in the future work. This paper proposed the influence coefficients of corrective MOD is only decided by qualitative analysis. And we also need to concentrate on the difference between the virtual and real world. For example, the load of the object also influences the maintenance time, because people do the same work in the different load are different, and existing method doesn't think of this, and the influence factor may exist interaction, which also need to be studied to predict the maintenance accurately.

\section{REFERENCE}

[1] P. C. Thomas and D. W. Mizell, "Augmented reality: An application of heads-up display technology to manual manufacturing processes," in Proc. the International Conference on Twenty-Fifth Hawaii, vol. 2, 1992.

[2] L. D. Cutler, B. Fröhlich, and P. Hanrahan, "Two-handed direct manipulation on the responsive workbench," in Proc. the Symposium on Interactive 3D Graphics, pp. 107-114, April 1997.

[3] W. Q. Hui and J. R. Li, "Interactive visualization of complex dynamic virtual environment for industrial assemblies," Computers in Industry, vol. 57, pp. 366-377, 2006.

[4] A. F. Abate, M. Guida, P. Leoncini, M. Nappi, and S. Ricciardi, "A haptic-based approach to virtual training for aerospace industry," Journal of Visual Languages and Computing, vol. 20 no. 1, pp. 318-25, 2009.

[5] A. G. D. Sa and G. Zachmann, "Virtual reality as a tool for verification of assembly and maintenance processes," Computers and Graphics, vol. 23, no. 1, pp. 389-403.1999.

[6] F. J. A. M. V. Houten, "The virtual maintenance system: a computer-based support tool for robust design," Product Monitoring, Fault Diagnosis and Maintenance Planning, pp. 91-94, 2000.

[7] H. C. N. Amos, J. Adolfsson, M. Sundberg, and L. J .D. Vin, "Virtual manufacturing for press line monitoring and diagnostics," Machine Tools and Manufacture, vol. 48, pp. 565-575, 2008.

[8] P. Bourdot, F. Picon, and M. Ammi, "VR-CAD integration: multimodal immersive interaction and advanced haptic paradigms for implicit edition of CAD models," Computer-aided Design, vol. 42, no. 5, pp. 445-461, 2008.

[9] L. J. Forsman, M. Kadefors, and R. R. Ortengren, "MTM-based ergonomic workload analysis," International Journal of Industrial Ergonomics, vol. 30-33, 2002.

[10] A. B. Segur, Motion Time Analysis, 1928.

[11] S. Lan, "Optimization of electric motor assembly operation with work study," in Proc. International Conference on the Logistics Systems and Intelligent Management, pp, 1101-1104, 2010.

[12] Z. Q. Ma, Q, Guangwei, S. Li , S. Yongcai, L. Peng, Y. C. Sun, "Research on the time quota of transmission gear based on MOD," in Proc. the 2nd International Conference on Information Science and Engineering (ICISE), pp, 3091-3094, 2010.

[13] M. Ishii and M. Sato, "A 3D interface device with force feedback: a virtual work space for pick-and-place tasks," Virtual Reality Annual International Symposium, pp, 331-335, 1993.

[14] N. Duffy, D. Allan, and J. T. Herd, "Real-time collision avoidance system for multiple robots operating in shared work-space," Computers and Digital Techniques, vol. 136, no. 6, pp, 478-484,1989.

[15] Y. F. Huang and K. Gupta, "An adaptive configuration-space and work-space based criterion for view planning, intelligent robots and systems," in Proc. the International Conference on Intelligent Robots and Systems, pp, 3366-3371, 2005.

[16] M. Hagberg, "Electromyography signs of shoulder muscular fatigue in two elevated arm position," Am J Phys Med, vol. 60, pp. 111-121, 1981.

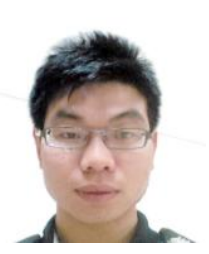

Zhou Xinxin was born in Beijing, in 1992. He received his master in maintainability, systems engineering, virtual maintenance from State Key Laboratory of Virtual Reality Technology and System, Beijing China.

Zhou Dong is a professor. He is a member of State Key Laboratory of Virtual Reality and the Reliability and Environmental Engineering, National Defense Key laboratory. He is research are maintainability, systems engineering, virtual maintenance institution: reliability engineering and system. 